\title{
MEDIA PEMBELAJARAN 35 SIRAH SHAHABIYAH BERBASIS ANDROID
}

\author{
Wiyanto \\ Program Studi Teknik Informatika, Sekolah Tinggi Teknologi Pelita Bangsa \\ wiyanto@pelitabangsa.ac.id
}

\begin{abstract}
Abstrak
Perkembangan pesat di dunia telekomunikasi dan digital, membuat perangkat selular kini menjadi sebuah kebutuhan primer bagi sebagian besar orang. Perangkat seluler berbasis android sudah menghasilkan berbagai media pembelajaran untuk masyarakat. Namun hal ini yang tidak menjadi prioritas untuk seorang muslim dalam belajar. Walaupun demikian pembelajaran menggunakan media berbasis android adalah cara yang mudah untuk diterapkan sebagai media pembelajaran. Diantaranya mengenal dan mempelajari Sirah Shahabiyah, dikarenakan karakteristik masyarakat terhadap minat belajar mengenal tentang Sirah Shahabiyah yang kurang maksimal, maka perlu adanya media pembelajaran yang memudahkan masyarakat dalam belajar. Oleh karena itu, aplikasi ini dapat berguna untuk memudahkan pengguna dan masyarakat dalam belajar mengenai Sirah Shahabiyah. Metode pengumpulan data pada penelitian ini yang digunakan yaitu dengan metode studi lapangan, studi pustaka, dan studi literatur sebelumnya. Sedangkan untuk metode pengembangan sistem menggunakan metode pengembangan sistem prototype, yang meliputi tahap planning, analisa, desain dan implementasi. Dan untuk pendekatan perancangan sistem, menggunakan Unified Modeling Language (UML). Hasil dari penelitian ini adalah berupa aplikasi pembelajaran Sirah Shahabiyah berbasis android yang memudahkan pengguna dan masyarakat dalam mempelajari tentang sirah shahabiyah, serta melalui aplikasi ini juga, kegiatan belajar-mengajar menjadi lebih mudah, menyenangkan dan efektif.
\end{abstract}

Kata Kunci : Aplikasi, Media Pembelajaran, Sirah Shahabiyah, UML dan Android.

\begin{abstract}
The rapid development in the telecommunications and digital world today makes android-based mobile devices basic needs for many people. The devices have even provided various kinds of learning media for the community. Further, even though the devices are easily to apply as learning media, they have not been a priority for Muslims in improving their knowledge, such as Sirah Shahabiyah (the journey of a female companion of the Prophet Muhammad). Due to the community's little interests in learning Sirah Shahabiyah, it is necessary to create a learning application that allows the user and the community to easily learn it. The methods used to collect the data of this research are field study, literature review and previous literature review. The system is developed using a prototype system development method consisting of the stages of planning, analysis, design and implementation and is designed using Unified Modeling Language (UML). The result of this research is a learning application in the form of android-based Sirah Shahabiyah, by which the user and the community can easily learn Sirah Sahabiyah, facilitating pleasant and effective learning activities.
\end{abstract}

Keywords: Application, Learning Media, Sirah Shahabiyah, UML and Android.

\section{PENDAHULUAN}

\section{Latar Belakang Masalah}

Perkembangan Ilmu Pengetahuan dan Teknologi (IPTEK) membuat sebagian orang memiliki tingkat mobilitas yang tinggi. Bahkan bisa dikatakan perangkat mobile adalah salah satu benda yang tidak dapat terpisahkan dari masyarakat di era modern ini.
Pengguna telepon seluler pun beragam, dari mulai orang dewasa sampai pada anak-anak yang sebenarnya belum membutuhkan perangkat keras tersebut. Sehingga banyak diantara mereka salah memanfaatkan fungsi dari perangkat seluler (handphone) tersebut, seperti menggunakan untuk bermain games secara 
terus menerus, bermain media sosial sepanjang hari, bahkan sampai pada melihat video-video porno.

Untuk belajar mengenai sirah shahibiyah dan sirah rosulullah harus didampingi oleh seorang ustadz atau ustadzah, yaitu dengan menggunakan metode pembelajaran deskriptif. Pengajar memberikan materi pembelajaran dan catatan-catatan untuk dihafal para murid lalu diujikan. Metode seperti ini sering sekali dilakukan oleh seorang guru terhadap muridnya. Sedangkan setiap murid berbeda-beda dalam menyerap pelajaran yang diberikan oleh pengajar. Untuk membantu para guru TPA (Taman Pendidikan Al-qur'an) dalam mengatasi permasalahan ini, saya selaku penulis melakukan penelitian dengan menggunakan media pembelajaran melalui perangkat smartphone. Smartphone yang sedianya sebagai alat komunikasi, saat ini sudah lebih dari fungsi dasarnya yang dulu hanya bisa menerima panggilan telepon dan SMS (short message service) saja.

Pada dunia pendidikan pun berkembang dengan memanfaatkan mobile application tersebut. Dengan membuat mobile application dibidang pendidikan yaitu memberikan materi mengenai pembelajaran yang dibuat dalam aplikasi tersebut. Dalam lingkungan sekolah, aplikasi ini dapat dimanfaatkan untuk mendukung proses pembelajaran, dimana dapat menambah panduan belajar tidak hanya mengandalkan materi yang didapat dari sekolah.

Penggunaan media smartphone dalam belajar mengenal 35 Sirah Shahibiyah bisa menjadikan belajar lebih efisien dan dengan media pembelajaran smartphone ini, semua kalangan dapat belajar mengenai Sirah Shahibiyah tanpa mengenal usia.

\section{Media Pembelajaran}

Media pembelajaran disebut juga sebagai proses belajar mengajar yang merupakan proses komunikasi. Media yang dimanfaatkan untuk belajar adalah media pembelajaran. Para ahli memberikan batasan pada media pembelajaran. AECT misalnya, yang berkata media pembelajaran yaitu sesuatu yang dimanfaatkan orang untuk memberikan pesan. Gagne mengatakan media adalah jenis komponen lingkungan pembelajaran untuk merangsang mereka belajar [1].

\section{Android}

Sistem operasi untuk perangkat Mobile menggunakan linux terdiri dari middleware, sistem operasi, dan aplikasi disebut sebagai Android. Android menghasilkan platform terbuka untuk pengembang menciptakan aplikasi. Android adalah sistem operasi yang digunakan pada satu miliar tablet dan smartphone [2].

As-sirah menurut bahasa adalah kebiasaan, jalan, cara, dan tingkah laku. Menurut istilah umum, artinya adalah perincian hidup seseorang atau sejarah hidup seseorang. Sedangkan Shahabiyah berarti sahabat wanita. Sahabat wanita Rasulullah adalah wanita-wanita terhebat dan agung pada zaman Rasulullah Muhammad SAW, yang merupakan generasi terbaik sepanjang sejarah peradaban Islam [3].

UML (Unified Modelling Language) adalah sebuah bahasa yang berdasarkan grafik atau gambar untuk memvisualisasikan, memberikan spesifikasi, membangun dan mendokumentasikan sebuah sistem pengembangan perangkat lunak berbasis Object Oriented Programming (OOP) [4].

\section{Tujuan Penelitian}

Adapun tujuan yang ingin dicapai oleh penulis dari penelitian ini adalah sebagai berikut:

1. Untuk meningkatkan minat belajar masyarakat termasuk bagi anak-anak dan remaja muslim untuk belajar 
mengenal sahabat perempuan rosulullah.

2. Untuk membantu masyarakat yang kesulitan dalam mencari waktu untuk belajar.

3. Membantu para pengajar TPA dan orang tua dalam memberikan atau menyampaikan tentang 35 sirah shahibiyah secara menarik, sehingga memberikan suasana belajar yang efesien dan menyenangkan.

\section{Manfaat Penelitian}

Adapun manfaat yang diperoleh penulis dari pembuatan aplikasi media pembelajaran 35 sirah shahibiyah berbasis android ini adalah sebagai berikut:

1. Untuk Masyarakat

Masyarakat dapat menggunakan media pembelajaran 35 sirah shahabiyah dengan metode pembelajaran yang efektif, menyenangkan dan mudah dalam menggunakan media samartphone berbasis android.

2. Untuk Peneliti

Penulis dapat mengembangkan ide dan merancang media pembelajaran 35 sirah shahabiyah berbasis android yang menarik.

\section{METODE PENELITIAN}

\section{Tempat Penelitian}

Penelitian ini dilakukan di MI Islamiyah Pasar Kec. Batang Kab. Brebes Jawa Tengah dan daerah sekitar Kabupaten Brebes.

\section{Metode Pengembangan Sistem}

Dalam penelitian ini, metode pengembangan sistem yang digunakan adalah model prototype. Adapun alasan penulis menggunakan metodologi ini karena lebih menghemat waktu dalam mengembangan sistem, pengembang dapat bekerja lebih baik dalam menentukan kebutuhan pengguna, penerapan menjadi lebih mudah karena pengguna mengetahui apa yang diharapkan.

Salah satu model yang digunakan untuk mengembangkan software adalah apabila user mendefinisikan serangkaian sasaran umum untuk software tersebut, akan tetapi tidak mengidentifikasikan kebutuhan output, pemrosesan, ataupun input secara detail, hal ini disebut dengan model prototype (prototyping paradigm).[5] Metode ini dimulai dengan pengumpulan suatu kebutuhan. Pengembang dan user bertemu dan mendefinisikan segala kebutuhan yang diketahui dan area garis besar dimana definisi lebih jauh merupakan sebuah keharusan, kemudian baru dilakukan perancangan secara cepat/kilat. Perancangan secara cepat focus pada penyajian aspek-aspek software tersebut, yang nampak untuk user (contoh pada pendekatan input dan output).

\section{Metode Perancangan Sistem}

Dengan menggunakan metode pendekatan berorientasi objek maka peneliti akan menggambarkan dengan menggunakan pemodelan Unified Modeling Language (UML).

\section{Penentuan Actor}

Adapun aktor yang terlibat pada sistem ini adalah user/pengguna. Pengguna langsung dapat melihat konten yang ada dalam aplikasi tersebut setelah menginstal aplikasi 35 sirah shahbiyah ini.

Tabel 1. Penentuan Aktor

\begin{tabular}{ccl}
\hline NO & \multirow{2}{*}{ Aktor } & \multicolumn{2}{c}{ Keterangan } \\
\hline 1. & User & $\begin{array}{l}\text { Adapun hak-hak yang bisa } \\
\text { dilakukan oleh aktor user } \\
\text { adalah pilih sirah, latihan } \\
\text { soal, Lanjut Membaca, } \\
\text { beranda, cara menggunakan, } \\
\text { tentang, dan keluar aplikasi. }\end{array}$ \\
\hline
\end{tabular}

\section{Use Case Diagram}

Diagram ini memperlihatkan himpunan Use-Case dan Aktor-aktor (jenis khusus dari kelas). Diagram ini penting untuk mengorganisasi dan memodelkan perilaku 
dari suatu sistem yang dibutuhkan serta diharapkan pengguna.

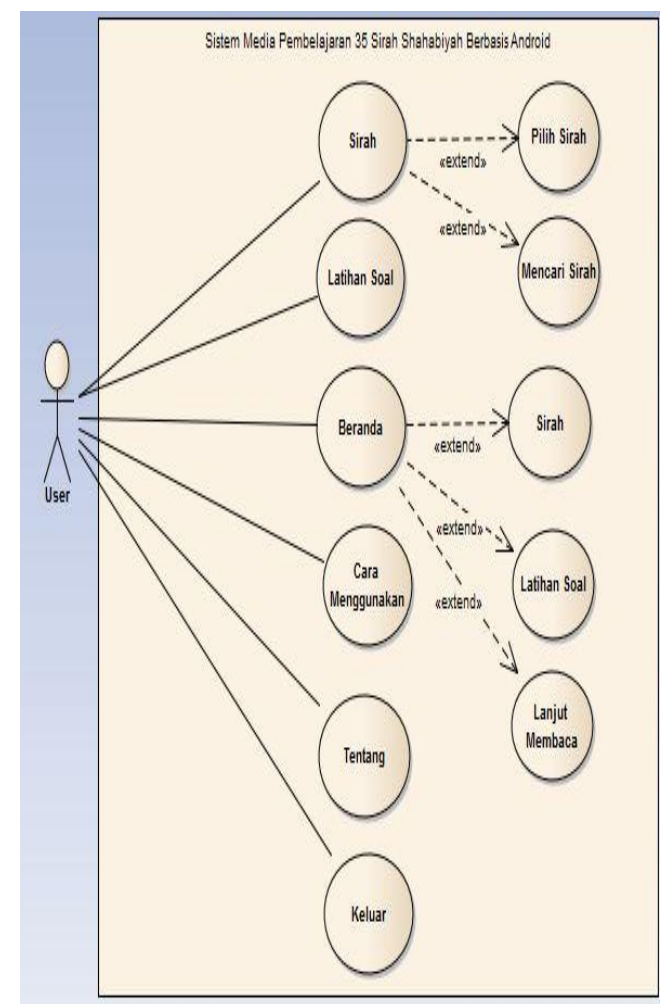

Gambar 1. Use Case

\section{HASIL DAN PEMBAHASAN}

\section{Spesifikasi Aplikasi}

Untuk menggunakan aplikasi Sirah Shahabiyah, terdapat beberapa spesifikasi sistem yang perlu diperhatikan oleh pengguna. Berikut ini adalah spesifikasi dari perangkat keras dan perangkat lunak yang harus diperhatikan, ialah sebagai berikut :

\section{Spesifikasi Perangkat Keras}

Spesifikasi perangkat keras yang direkomendasikan untuk menggunakan aplikasi ini adalah sebagai berikut :

$\checkmark$ Memiliki processor dengan kapasitas minimal $1 \mathrm{GHz}$.

$\checkmark$ Memiliki memori internal ataupun memory card dengan kapasitas minimal $500 \mathrm{MB}$.

$\checkmark$ Memiliki resolusi layar minimal $480 \times 800$ pixel.

\section{Spesifikasi Perangkat Lunak}

Spesifikasi perangkat lunak yang disarankan untuk aplikasi ini adalah sistem operasi minimum android 4.0 (Ice Cream Sandwich). Namun sistem operasi yang direkomendasikan adalah sistem operasi diatas 4.2 (Jelly Bean).

\section{Spesifikasi Perangkat Jaringan}

Aplikasi Sirah Shahabiyah ini membutuhkan koneksi internet hanya pada saat melakukan penginstalan aplikasi saja, selanjutnya ketika aplikasi sudah terinstal, pengguna dapat menggunakan aplikasi ini tanpa koneksi internet, Kecuali jika ada pembaharuan aplikasi, pengguna membutuhkan koneksi internet untuk melakukan pembaharuan.

\section{Prosedur Operasional}

Media pembelajaran ini dikembangkan berupa aplikasi android yang dapat dijalankan pada perangkat bergerak berbasis android. Sehingga media pembelajaran yang dikembangkan dapat dijalankan kapanpun dan dimanapun. Media pembelajaran ini termasuk dalam kategori media pembelajaran berbasis mobile learning. Dibutuhkan mobile device dengan sistem operasi android minimum versi 4.0 .

\section{Halaman Menu Utama atau Beranda}

Halaman pertama yang ditampilkan saat pengguna membuka aplikasi Sirah Shahabiyah adalah halaman menu awal atau beranda. Pada halaman ini terdapat dua button yaitu "Sirah" dan "Latihan Soal". 


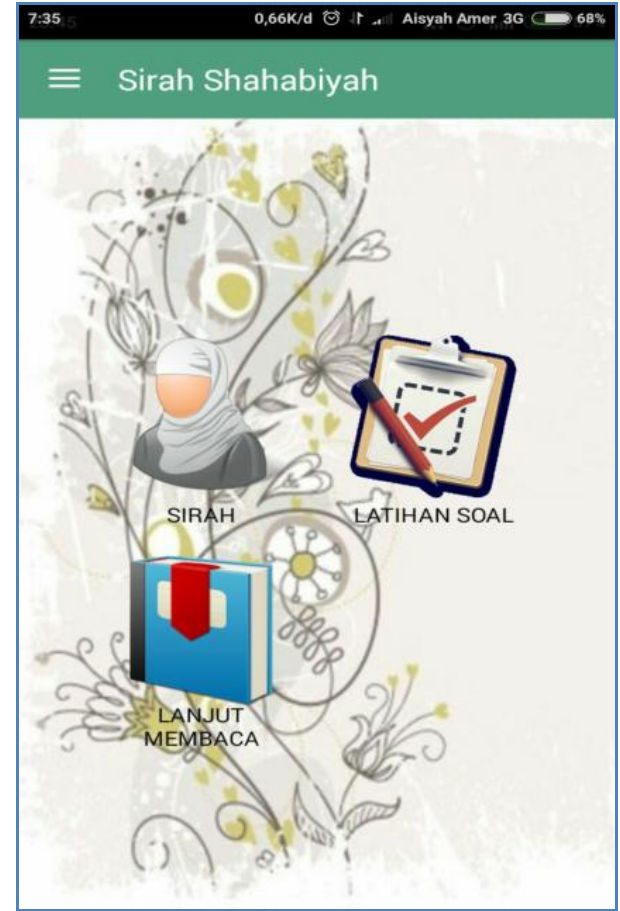

\section{Gambar 2. Tampilan Menu Utama}

\section{Halaman Sirah}

Halaman ini menampilkan nama-nama 35 Sirah Shahabiyah yang ada pada aplikasi ini. Untuk membaca sirah, pengguna harus memilih salah satu nama Shahabiyah yang ada pada halaman Sirah.

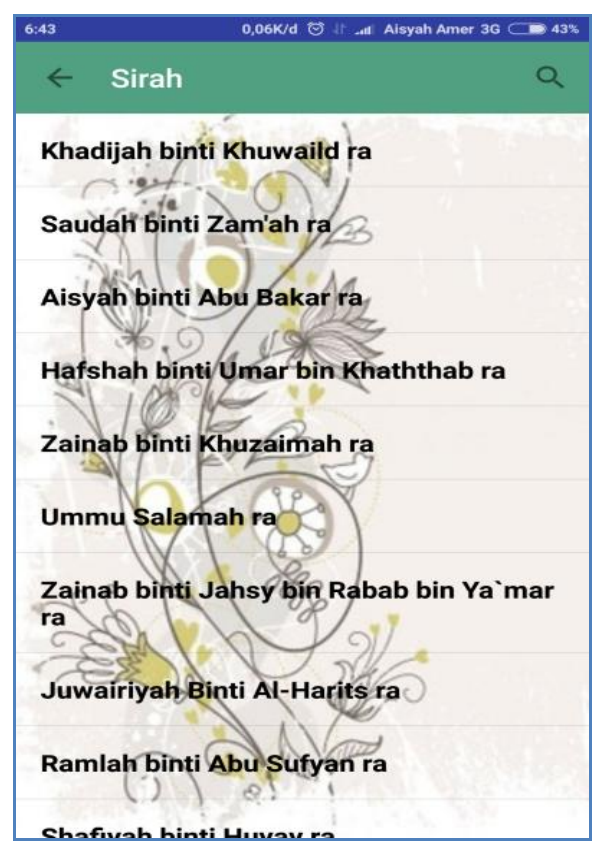

Gambar 3. Tampilan Halaman Sirah

\section{Halaman Pencarian Sirah}

Halaman ini digunakan untuk memudahkan pengguna mencari nama Shahabiyah yang ingin dibaca terlebih dahulu, tanpa harus mencari satu persatu nama Shahabiyah pada halaman Sirah.

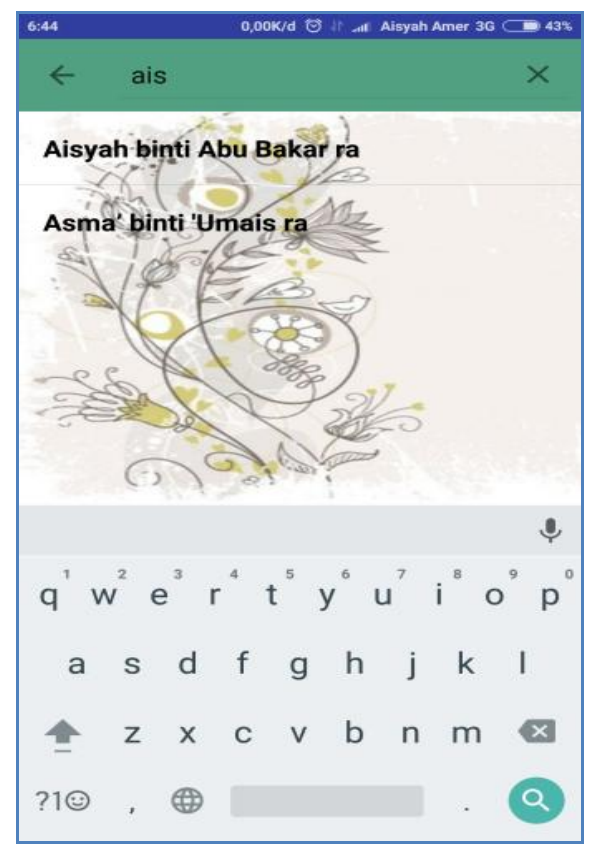

\section{Gambar 4. Tampilan Halaman Pencarian Sirah}

\section{Halaman Sirah Shahabiyah}

Pada halaman ini menampilkan isi dari Sirah Shahabiyah. Contohnya tampilan sirah shahabiyah untuk sirah dari "Aisyah binti Abu Bakar ra”.

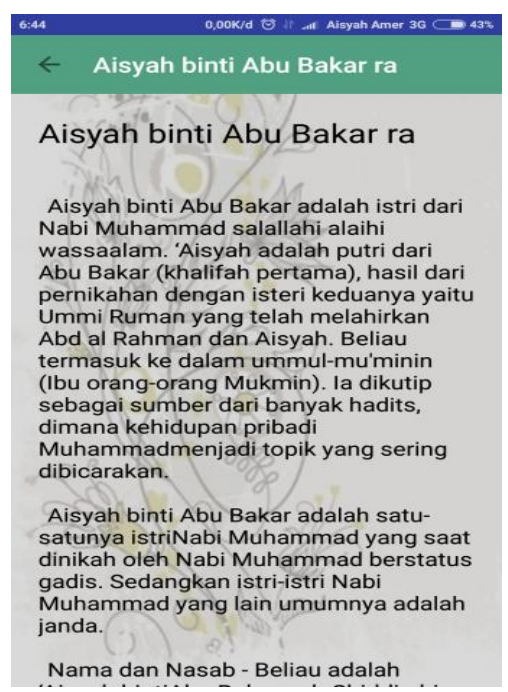

\section{Gambar 5. Halaman Sirah Shahabiyah}




\section{Halaman Pilihan Layanan Aplikasi}

Pada halaman ini berisikan pilihan tomboltombol pada aplikasi Sirah Shahabiyah. Yaitu "beranda" untuk kembali ke halaman utama aplikasi, "cara menggunakan" berisi tentang prosedur penggunaan aplikasi, "tentang" berisi informasi seputar aplikasi, dan "keluar" untuk keluar dari aplikasi.

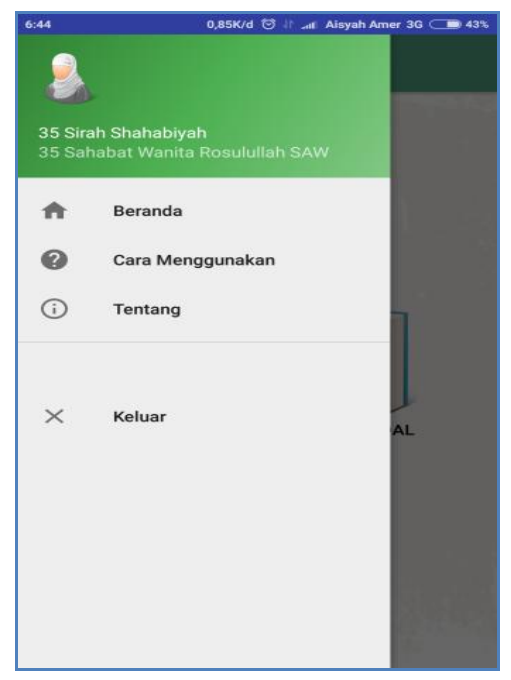

\section{Gambar 6. Halaman Pilihan Layanan Aplikasi}

\section{Halaman Cara Menggunakan}

Pada halaman ini berisikan tentang prosedur penggunaan aplikasi 35 Sirah Shahabiiyah. Layanan ini bertujuan agar pengguna tidak mengalami kesulitan saat menggunakan aplikasi ini.

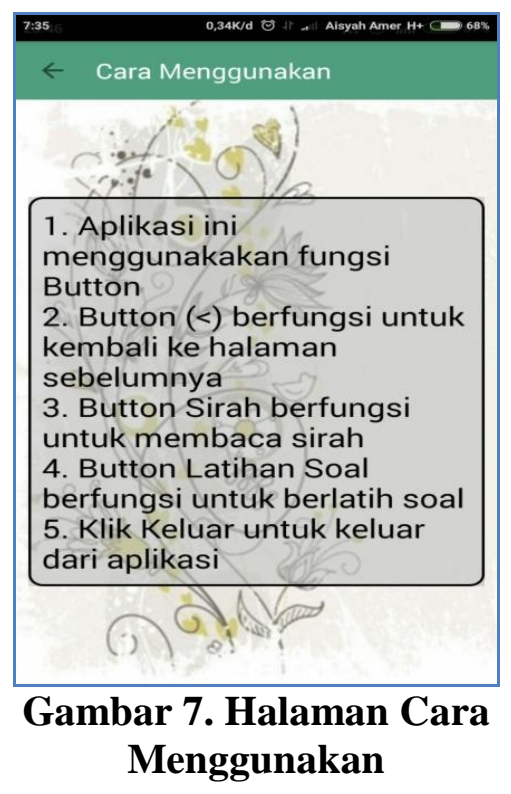

\section{Halaman Tentang}

Halaman ini berisi informasi seputar aplikasi Sirah Shahabiyah, layanan ini bertujuan agar pengguna dapat mengetahui apa saja yang ada di dalam aplikasi ini.

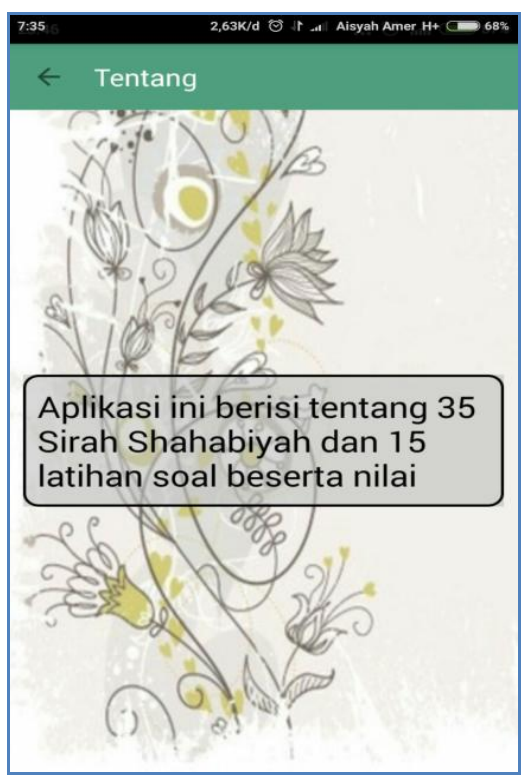

\section{Gambar 8. Halaman Tentang}

\section{Halaman Latihan Soal}

Halaman ini berisi 15 latihan soal yang harus dijawab oleh pengguna, pertanyaan yang ada pada aplikasi ini hanya seputar Sirah Shahabiyah. Ke 15 soal harus diselesaikan tepat pada waktu yang sudah ditentukan.

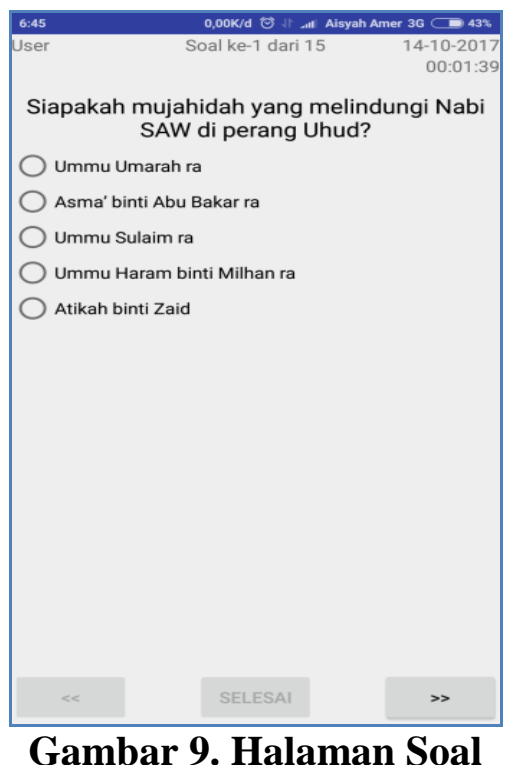

Gambar 9. Halaman Soal 


\section{Halaman Selesai pada Latihan Soal}

Halaman ini menampilkan button "selesai" ketika ke lima belas soal pada aplikasi Sirah Shahabiyah sudah dijawab.

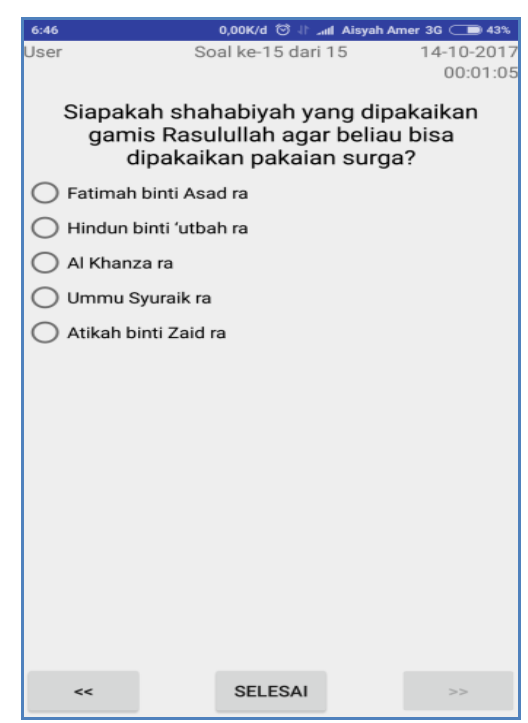

\section{Gambar 10. Halaman Selesai pada Latihan Soal}

\section{Halaman Pemberitahuan Nilai}

Pada halaman ini akan menampilkan nilai sekaligus denga nomor soal yang salah dalam menjawab. Pada halaman pemberitahuan nilai hanya akan tampil ketika semua soal sudah terjawab.

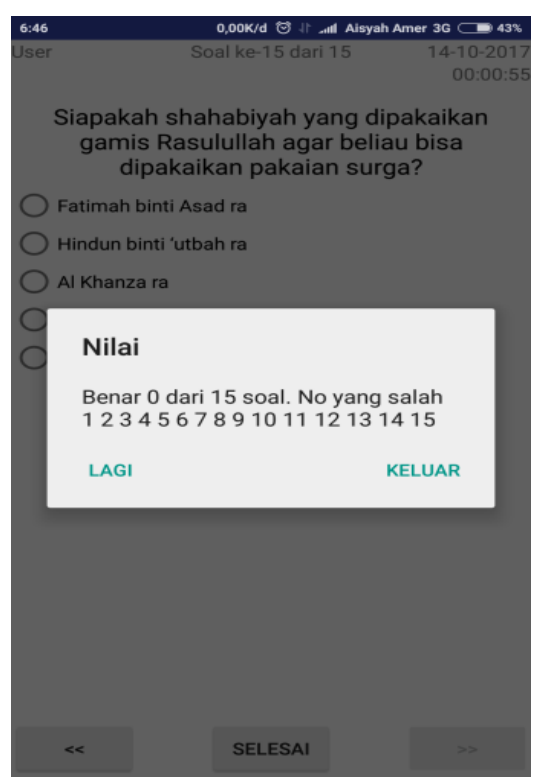

Gambar 11. Halaman Pemberitahuan

\section{Nilai Halaman Dialog Keluar}

Pada aplikasi Sirah Shahabiyah ini memberikan dialog pada saat pengguna memilih keluar dari aplikasi.

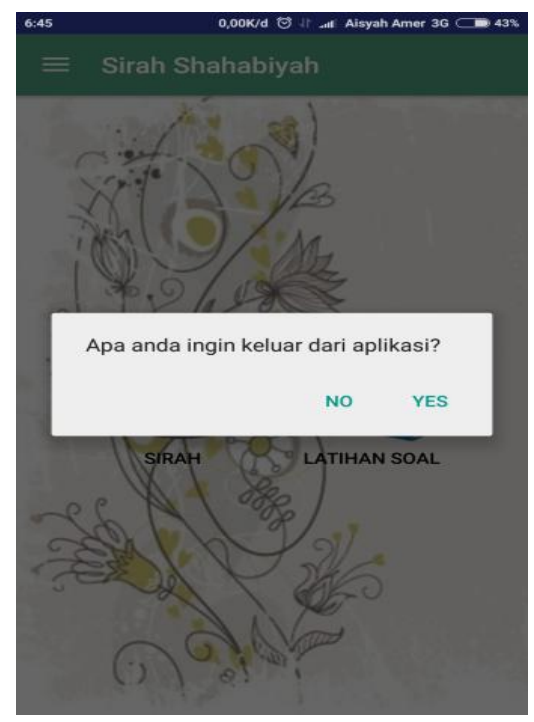

\section{Gambar 12. Halaman Dialog Keluar}

\section{SIMPULAN}

Dari hasi penelitian ini penulis menarik beberapa simpulan antara lain :

1. Aplikasi media pembelajaran berbasis android ini merupakan media yang berguna untuk membantu murid dan masyarakat lainnya dalam mempelajari tentang Sirah Shahabiyah.

2. Melalui Aplikasi ini, kegiatan belajar Sirah Shahabiyah menjadi suatu hal yang menyenangkan dan efektif karena dirancang dengan tampilan yang menarik.

3. Murid dan masyarakat tidak lagi mengalami kesulitan dalam membelajari tentang sirah shahabiyah, karena sudah ada dalam bentuk aplikasi.

\section{UCAPAN TERIMA KASIH}

Terima kasih kepada Sekolah Tinggi Teknologi Pelita Bangsa dan semua pihak 
yang telah memberikan dukungan baik secara material maupun spiritual sehingga penelitian ini dapat terlaksana dan diterbitkan dijurnal ini.

\section{DAFTAR PUSTAKA}

[1] Falahudin, Iwan. Pemanfaatan Media dalam Pembelajaran. Jurnal Lingkar Widyaiswara, Edisi 1 No. 4, p.104 117, ISSN: 2355-4118. Oktober Desember 2014

[2] Fithri, Laily, Diana dan Setiawan, Andre, Dave. Analisa dan Perancangan Game Edukasi Sebagai
Motivasi Belajar Untuk Anak Usia Dini. Jurnal SIMETRIS, Vol 8 No 1 April 2017

[3] Al-Mishri Mahmud. 35 Sirah Shahabiyah. Al-Itishom Cahaya Umat. Jakarta. 2013.

[4] Tohari Hamim. 2014. Astah (Analisis serta Perancangan Sistem Informasi melalui Pendekatan UML). Andi. Yogyakarta.

[5] Pressman, Roger., Software Engineering: A practitioner's approach, The McGraw-Hill Companies,Inc, 2001. 